\title{
Adverse effects of nephrectomy
}

\author{
Denis A. Cozzi $^{1} \cdot$ Silvia Ceccanti $^{1} \cdot$ Francesco Cozzi $^{1}$
}

Received: 14 November 2015 /Revised: 16 November 2015 / Accepted: 14 December 2015 /Published online: 30 March 2016

(C) IPNA 2016

Dear Editor,

We read the interesting paper by Mavinkurve-Groothuis et al. in Pediatric Nephrology [1]. The authors compared renal-injury markers of surviving patients who underwent nephrectomy for unilateral Wilms tumor (UWT) with a matched group of patients who underwent nephrectomy for nononcological causes. Renal injury signs were found in $54 \%$ of patients who underwent nephrectomy for nononcological causes and in $23 \%$ of UWT survivors after a follow-up of 15 years $(p=0.004)$.

We do agree that the prevalence of "progressive" renal injury in UWT survivors may be underestimated. We previously reported that the mean \pm standard deviation (SD) estimated glomerular filtration rate (eGFR) in UWT survivors decreases significantly with age $\left(88.1 \pm 22.6 \mathrm{ml} / \mathrm{min} / 1.73 \mathrm{~m}^{2}\right.$ during the third decade after surgery and $66.6 \pm 15.6 \mathrm{ml} / \mathrm{min} /$ $1.73 \mathrm{~m}^{2}$ during the fifth decade after surgery $(p=0.02)$ (reference 18 in the article). Similarly, Kenny et al. reported that UWT survivors $>50$ years presented an association between nephrectomy and blood hypertension that was not present in the same cohort of patients at a median age of 29 years [2]. These findings are relevant because population studies indicate that even mild-to-moderate renal injury is associated with increased morbidity and mortality risks [3]. Indeed, recent studies indicate that kidney donors present at long-term fol-

Denis A. Cozzi

da.cozzi@uniroma1.it

1 Pediatric Surgery Unit, Sapienza University of Rome, Azienda Policlinico Umberto I, Rome RM 00161, Italy low-up an increased risk for cardiovascular disease, end-stage renal disease, and overall mortality $[4,5]$.

The adverse effects of nephrectomy seem to overweight the reported adverse effects of nephron-sparing surgery for treating UWT. The hope is that a conservative surgical approach, when feasible, may prevent renal injury.

\section{Compliance with ethical standards}

Conflict of interest All the authors state that there are no direct or indirect commercial financial incentive associated with publishing present work.

\section{References}

1. Mavinkurve-Groothuis AMC, van de Kracht F, Westland R, van Wijk JA, Loonen JJ, Schreuder MF (2015) Long-term follow-up of blood pressure and glomerular filtration rate in patients with a solitary functioning kidney: a comparison between Wilms tumor survivors and nephrectomy for other reasons. Pediatr Nephrol 31:435441. doi:10.1007/s00467-015-3215-2

2. Kenney LB, Nancarrow CM, Najita J, Vrooman LM, Rothwell M, Recklitis C, Li FP, Diller L (2010) Health status of the oldest adult survivors of cancer during childhood. Cancer 116:497-505

3. Mafham M, Emberson J, Landray MJ, Wen CP, Baigent C (2011) Estimated glomerular filtration rate and the risk of major vascular events and all-cause mortality: a meta-analysis. PLOS ONE 6, e25920

4. Mjøen G, Hallan S, Hartmann A, Foss A, Midtvedt K, Oyen O, Reisæter A, Pfeffer P, Jenssen T, Leivestad T, Line PD, Ovrehus M, Dale DO, Pihlstrøm H, Holme I, Dekker FW, Holdaas H (2014) Long-term risks for kidney donors. Kidney Int 86:162-167

5. Muzaale AD, Massie AB, Wang MC, Montgomery RA, McBride MA, Wainright JL, Segev DL (2014) Risk of end-stage renal disease following live kidney donation. JAMA 311:579-586 